\title{
Using a Multitheory Model to Predict Initiation and Sustenance of Fruit and Vegetable Consumption Among College Students
}

Manoj Sharma, PhD; Philip M. Stephens, MS, OMS I; Vinayak K. Nahar, MD, PhD, MS, FRSPH; Hannah Priest Catalano, PhD, CHES; Vimala C. Lingam, MPharm, MPH; M. Allison Ford, PhD

From the Department of Behavioral and Environmental

Health at Jackson State University in Mississippi (Dr Sharma and Ms Lingam); the Lincoln Memorial University DeBusk College of Osteopathic

Medicine in Harrogate, Tennessee (Student Doctor Stephens and Dr Nahar); the Center for Animal and Human Health, the College of Veterinary Medicine, and the School of Mathematics and Science at Lincoln Memorial University in

Harrogate, Tennessee (Dr Nahar); the School of Health and Applied Human Sciences at the University of North Carolina in Wilmington (Dr Catalano); and

the Department of Health,

Exercise Science, and Recreation Management at the University of Mississippi in Oxford (Dr Ford).

Financial Disclosures: None reported.

Support: None reported.

Address correspondence to Vinayak K. Nahar, MD, PhD, MS, FRSPH, Lincoln Memorial University, College of Veterinary Medicine, Center for Animal and Human Health in Appalachia, 6965 Cumberland Gap Pkwy, Harrogate, TN 37752-8245.

Email: naharvinayak@gmail.com Submitted October 30, 2017; final revision received February 7, 2018; accepted February 13, 2018.
Context: Consuming a diet rich in fruits and vegetables offers numerous health benefits. However, many college students do not consume the recommended amount of fruits and vegetables daily.

Objective: To predict change in fruit and vegetable consumption behavior among college students who were not eating the recommended amount of fruits and vegetables using the multitheory model (MTM) of behavior change.

Methods: In this cross-sectional study, a 38-item face-, content-, and constructvalid survey was sent to college students at a large university in the southeastern United States. Students were included in the analysis if they were aged at least 18 years and ate less than 5 cups of fruits and vegetables per day. The survey was broken into sections based on the MTM constructs of initiation of behavior change (participatory dialogue, behavioral confidence, and changes in physical environment) and sustenance of behavior change (emotional transformation, practice for change, and changes in social environment). Stepwise multiple regression was conducted to predict behavior change regarding fruit and vegetable consumption.

Results: Of the 5000 potential respondents, 175 completed the survey and were included in the analysis. Behavioral confidence and changes in physical environment were statistically significant predictors of the intention to initiate fruit and vegetable consumption $\left(F_{2,173}=59.700 ; P<.001\right)$ and accounted for $40.2 \%$ of the variance. Emotional transformation, practice for change, and changes in social environment were statistically significant predictors for the intention to sustain fruit and vegetable consumption $\left(F_{3,171}=26.374 ; P<.001\right)$ and accounted for $30.4 \%$ of the variance.

Conclusion: Survey results showed that the MTM is a useful framework for designing behavior change interventions to promote fruit and vegetable consumption among college students.

J Am Osteopath Assoc. 2018;118(8):507-517

doi:10.7556/jaoa.2018.119

Keywords: diet, fruits and vegetables, multitheory model, nutrition

onsuming a diet rich in fruits and vegetables can lower the risk of heart disease, stroke, hypertension, type 2 diabetes mellitus, some types of cancer, vision problems, and gastrointestinal tract issues. ${ }^{1-6}$ Eating fruits and vegetables that are high in fiber and low in calories may also help prevent obesity. ${ }^{7}$ Fruits and vegetables 
provide dietary fiber; vitamins; minerals, such as potassium, selenium, and manganese; and phytochemicals that provide protection against chronic diseases, such as terpenes, carotenoids, flavonoids, and lycopene. ${ }^{8}$ The United States Department of Agriculture (USDA) recommends that women aged 19 to 30 years consume 2 and a half cups of vegetables and 2 cups of fruit per day and that men aged 19 to 30 years consume 3 cups of vegetables and 2 cups of fruit per day. ${ }^{9,10}$ Larger amounts of fruits and vegetables are recommended for people who engage in more than 30 minutes of moderate physical activity per day. 9,10

Many college students engage in poor dietary behavior, including low fruit and vegetable consumption. ${ }^{11,12}$ A nationally representative survey ${ }^{13}$ reported that $4.2 \%$ of college students in the United States ate 5 or more servings of fruits and vegetables per day and $63.0 \%$ ate 1 to 2 servings of fruits and vegetables per day. Another study ${ }^{12}$ reported that $85.1 \%$ of college students in the United Kingdom failed to consume the recommended daily servings of fruits and vegetables. ${ }^{12}$ Low fruit and vegetable consumption contributes to poor nutritional status and puts college students at risk for many negative health outcomes, including obesity. In 2016, 23.3\% of college students in the United States were overweight and $14.6 \%$ were obese. ${ }^{13}$

Dietary habits that are established during college will likely continue into the adult years. ${ }^{14}$ Therefore, it is essential to identify modifiable factors that influence fruit and vegetable consumption among college students and develop interventions that will effectively change behavior in this population. Determinants of fruit and vegetable consumption in college students have previously been studied. Blanchard et $\mathrm{al}^{15}$ used the theory of planned behavior and found that affective attitude and perceived behavioral control were significant predictors of fruit and vegetable consumption in college students. A study ${ }^{16}$ conducted in Quebec also found that perceived behavioral control was a significant predictor of fruit and vegetable consumption among college students. Another study ${ }^{17}$ found that environmental factors, such as housing with food provi- sion and access to a vehicle, were important determinants of college students' fruit and vegetable consumption. A secondary data analysis study ${ }^{18}$ found that fruit and vegetable consumption was associated with seatbelt and helmet use, perceived health, self-care behaviors, physical activity behavior, sleep patterns, and grades.

Several interventions for changing dietary behaviors in college students have also been studied. Kelley et $\mathrm{al}^{19}$ performed a systematic review of 14 dietary interventions in college students and concluded that interventions that included self-regulation components, such as goal setting and self-monitoring, and environmental approaches could be effective. Deliens et $\mathrm{al}^{20}$ conducted a systematic review of dietary interventions in college students and suggested that low-cost nutrition education that builds self-regulation skills may be effective in increasing fruit and vegetable consumption in this group.

Results of these studies ${ }^{15-20}$ show that personal and environmental factors are important antecedents for predicting fruit and vegetable consumption in college students. The multitheory model (MTM) of health behavior change, which incorporates both of these dimensions, has been proposed ${ }^{21,22}$ and applied to a variety of health behaviors in college students. ${ }^{23-26}$ The theory breaks down behavior change into 2 factors: initiation and sustenance. Initiation of behavior change includes the constructs of participatory dialogue (in which advantages offset disadvantages), behavioral confidence (futuristic projection of one's capability to perform a given behavior derived from internal and external sources); and changes in physical environment (access to resources). Sustenance of behavior change includes the constructs of emotional transformation (converting feelings into goals); practice for change (active reflection and reflective action); and changes in social environment, such as social support from family, friends, and health care professionals. ${ }^{21}$ The purpose of this study was to predict change in fruit and vegetable consumption behavior in college students who were not eating the recommended amount of fruits and vegetables using the MTM. 


\section{Methods}

In this cross-sectional study, the independent variables were the constructs of the MTM (initiation and sustenance) and the dependent variables were the intentions to initiate and sustain the consumption of 5 cups of fruits and vegetables every day. A randomly selected sample of students from a large public university in the southeastern United States was recruited to participate through an email that included a link to the 38-item survey. The Survey took about 10 to 15 minutes to complete. Content and construct validity of the survey was established by a panel of 6 experts (including H.P.C. and M.A.F.) from January 2016 to April 2016. The face-, content-, and construct-valid survey was administered during the spring 2017 semester via an online platform, which included informed consent. Data were collected over a 3-week period, with reminders sent out after the first and second weeks. Students were required to be aged at least 18 years participate.

The first survey item prompted students who reported that they consumed 5 or more cups of fruits or vegetables during the past 24 hours to stop the survey. The next 7 items of the survey collected sociodemographic data. The remaining 29 items were based on the MTM constructs of initiation of behavior change (participatory dialogue, behavioral confidence, and changes in physical environment) and sustenance of behavior change (emotional transformation, practice for change, and changes in social environment). Of these 29 items, 27 were divided into sections regarding each construct, and the final 2 items measured the students' intention to initiate and sustain the consumption of 5 cups of fruits and vegetables per day.

\section{Initiation of Behavior Change}

The participatory dialogue section of the survey included 10 items that asked students to rank how often advantages and disadvantages to eating 5 cups of fruits and vegetables each day would occur. Advantages included being healthy, having variety in meals, managing weight, having more energy, and having tasty food. Disadvantages included not having enough protein in their diet, being hungry most of the time, having less energy, having more food-related expenses, and enjoying meals less. Responses were rated on a 5-point Likert scale ranging from 0 (never) to 4 (always). Response values were combined to produce total scores for participatory dialogue advantages and disadvantages, each ranging from 0 to 20. Participatory dialogue disadvantage scores were then subtracted from advantage scores to calculate an overall participatory dialogue score, which ranged from a possible -20 to 20 .

Behavioral confidence was measured with 5 items that asked students to rank their level of surety that they would consume 5 cups of fruits and vegetables every day that week, consume 5 cups of fruits and vegetables every day while maintaining their budget, consume 5 cups of fruits and vegetables every day while enjoying their meals, consume 5 cups of fruits and vegetables every day without getting fed up with food, and consume 5 cups of fruits and vegetables every day without feeling hungry. Responses were ranked on a 5-point Likert scale ranging from 0 (not at all sure) to 4 (completely sure). Response values were combined to produce a total behavioral confidence score ranging from 0 to 20 .

Changes in physical environment were measured with 3 items that asked students how sure they were that they would have fruits and vegetables available for all meals, be able to eat fruits and vegetables at a restaurant, and be able to afford fruits and vegetables for meals. Responses were ranked on a 5-point Likert scale ranging from 0 (not at all sure) to 4 (completely sure). Response values were totaled to produce a change in physical environment score ranging from 0 to 12 .

Intention to initiate consuming 5 cups of fruits and vegetables each day was measured with 1 item that asked, "How likely is it that you will eat five cups of fruits and vegetables every day in the upcoming week?" Responses were ranked on a 5-point Likert scale ranging from 0 (not at all likely) to 4 (completely likely). 


\section{Sustenance of Behavior Change}

Emotional transformation was measured with 3 items. These items asked students to rank their level of surety with their ability to direct feelings/emotions toward the goal of eating 5 cups of fruits and vegetables each day, motivate themselves to eat 5 cups of fruits and vegetables each day, and overcome self-doubt in accomplishing the goal of eating 5 cups of fruits and vegetables each day. Responses were ranked on a 5-point Likert scale ranging from 0 (not at all sure) to 4 (completely sure). Response values were combined to produce a score for emotional transformation ranging from a possible 0 to 12 .

Practice for change was measured with 3 items that asked students how sure they were that they would keep a diary to monitor eating 5 cups of fruits and vegetables every day, eat 5 fruit cups of fruits and vegetables every day even if they encountered barriers, and rectify their plan to consume 5 cups of fruits and vegetables every day if they faced difficulties. Responses were ranked on a 5-point Likert scale ranging from 0 (not at all sure) to 4 (completely sure). Response values for the 3 items were combined to produce a practice for change score that ranged from 0 to 12 .

Changes in social environment was measured with 3 items that asked students to rank their level of surety that they could get the help of a family member, friend, and health care professional to support them with consuming 5 cups of fruits and vegetables every day. Responses were ranked on a 5-point Likert scale ranging from 0 (not at all sure) to 4 (completely sure). Response values were combined to produce a practice for change score ranging from 0 to 12 .

Intention to sustain the consumption of 5 cups of fruits and vegetables per day was measured with 1 item that asked, "How likely is it that you will eat 5 cups of fruits and vegetables every day from now on?" The response was ranked on a 5-point Likert scale ranging from 0 (not at all likely) to 4 (completely likely).

\section{Statistical Analysis}

All data were analyzed using SPSS version 23 (IBM). Descriptive statistics for sociodemographic and the
MTM constructs were conducted. Frequencies and percentages were calculated for categorical variables, and mean (SD) was calculated for metric variables. Internal consistency of the MTM subscales was measured using Cronbach $\alpha$, and confirmatory factor analysis was used for construct validation. ${ }^{27,28}$ The criterion for Cronbach $\alpha$ to be acceptable was $0.70 .{ }^{27}$ The criteria for the MTM subscales to be construct valid were eigenvalues greater than 1 and factor loadings for each item greater than $0.32 .^{28}$ Pearson product moment correlation was performed to assess direction and strength of the association between initiation and sustenance and their corresponding constructs. The core assumptions of multiple regression (ie, normality, linearity, homoscedasticity, independence of residuals, and multicollinearity) were checked. After each assumption was tested and no violations were recognized, stepwise multiple regression was carried out to predict initiation and sustenance of behavior change based on their respective constructs. There was not enough power to control for demographic variables, so they were not included in regression modeling.

The a priori criteria of probability of $F$ to enter the predictor in the model was less than or equal to 0.05 , and, for removing the predictor, greater than or equal to 0.10 . Based on aforementioned criteria, participatory dialogue was eliminated from the final initiation model. Construct validation through confirmatory factor analysis $^{29}$ was done on all of the subscales measuring constructs of the MTM. All subscales confirmed 1-factor solutions with eigenvalues over 1 and factor loadings for individual items over 0.50 , except for the participatory disadvantages subscale. The disadvantages subscale item that asked students to rank how often they would have more food-related expenses if they ate 5 or more cups of fruits and vegetables per day revealed a factor loading below 0.50 and loaded on a second factor. Because this was a new scale, and content and construct validity had been established by a panel of experts, it was deemed appropriate to retain this item in the analysis and not sacrifice content validity. No construct was eliminated from the final sustenance 
model. A minimum of 160 students were needed to achieve a .05 significance level, .80 level of power, and effect size of 0.07 (small to medium). Statistical significance was defined as $P \leq .05$. Incomplete surveys were not included in the analysis.

\section{Results}

Of the 5000 randomly selected students emailed, 437 began the guestionnaire of these 437 students, and 198 consumed at least 5 cups of fruits and vegetables per day. Of the remaining 289 respondents, 175 did not consume the recommended 5 or more cups of fruits and vegetables, were at least 18 years of age, and completed the survey. The mean (SD) age of the students who completed the survey was 20.5 (4.6) years. The ratio of men to women was $29(16.6 \%)$ to 146 (83.4\%), respectively. Additional student sociodemographic information is presented in Table 1. The majority of the students were white (136 [77.7\%]), freshmen (95 [54.3\%]), had an overall grade point average of 3.50 to 4.00 (89 [50.9\%]), lived on campus (115 [65.7\%]), and did not work (128 [73.1\%]).

Table 2 shows the mean (SD) scores of each MTM construct. The mean intention for initiation and sustenance of behavior change scores (range: 0-4) were 1.2 and 1.0, respectively. The mean participatory dialogue score (range: -20 to 20 ) was 7.0 . The mean behavioral confidence score was 6.8 out of a possible 20. The mean scores of constructs within the sustenance model (range, 0-12) were as follows: emotional transformation, 5.6; practice for change, 3.5; and changes in social environment, 5.9. A cross tabulation of constructs by gender and comparative $t$ tests revealed a statistically significant difference in changes in social environment between men and women, in which the mean (SD) score was 4.0 (2.7) for men and 6.8 (3.8) for women $(P=.003)$.

Table 3 shows the correlations between intention to initiate behavior change and the 3 MTM initiation constructs. Intention to initiate behavior change regarding fruit and vegetable consumption was significantly associated with the constructs of participatory dialogue ( $r=0.31 ; P<.001)$, behavioral confidence $(r=0.61$;
Table 1.

Sociodemographic Characteristics of College Students Who Participated in a Survey Regarding Fruit and Vegetable Consumption $(\mathbf{N}=175)$

\begin{tabular}{|c|c|}
\hline Characteristic & No. (\%) \\
\hline \multicolumn{2}{|l|}{ Gender } \\
\hline Male & $29(16.6)$ \\
\hline Female & $146(83.4)$ \\
\hline \multicolumn{2}{|l|}{ Race/Ethnicity } \\
\hline White & $136(77.7)$ \\
\hline Black & $21(12.0)$ \\
\hline Asian American & $7(4.0)$ \\
\hline Hispanic & $3(1.7)$ \\
\hline Other & $8(4.6)$ \\
\hline \multicolumn{2}{|l|}{ Class Level } \\
\hline Freshmen & $95(54.3)$ \\
\hline Sophomore & $36(20.6)$ \\
\hline Junior & $32(18.3)$ \\
\hline Senior & $12(6.9)$ \\
\hline \multicolumn{2}{|c|}{ Overall Grade Point Average } \\
\hline $2.00-2.49$ & $12(6.9)$ \\
\hline $2.50-2.99$ & $27(15.4)$ \\
\hline $3.00-3.49$ & $47(26.9)$ \\
\hline $3.50-4.00$ & 89 (50.9) \\
\hline \multicolumn{2}{|c|}{ Living Arrangements } \\
\hline On campus & $115(65.7)$ \\
\hline Off campus & $60(34.3)$ \\
\hline \multicolumn{2}{|l|}{ Work Status } \\
\hline Yes & $47(26.9)$ \\
\hline No & $128(73.1)$ \\
\hline
\end{tabular}

$P<.001)$, and changes in physical environment $(r=0.46$; $P<.001)$. Table 4 shows the correlations between intention to sustain behavior change and the 3 MTM sustenance constructs. Intention to sustain behavior change regarding fruit and vegetable consumption was significantly associated with emotional transformation ( $r=0.46 ; P<.001)$, practice for change $(r=0.52 ; P<.001)$, and changes in social environment $(r=0.38 ; P<.001)$. 
Table 2.

Multitheory Model Construct Survey Scores of College Students Who Do Not Consume at Least 5 Cups of Fruits and Vegetables Per Day $(\mathbf{N}=175)$

\begin{tabular}{lccc} 
Constructs & Range $^{\mathrm{a}}$ & Mean (SD) & Cronbach $\alpha$ \\
\hline Initiation & $0-4$ & $1.2(1.1)$ & $\ldots$ \\
\hline Participatory dialogue & & & \\
\hline Overall & -20 to 20 & $7.0(5.1)$ & $\ldots$ \\
\hline Advantages & $0-20$ & $14.5(3.1)$ & 0.80 \\
\hline Disadvantages & $0-20$ & $7.6(3.2)$ & 0.70 \\
\hline Behavioral confidence & $0-20$ & $6.8(5.3)$ & 0.88 \\
\hline Changes in physical environment & $0-12$ & $5.6(3.4)$ & 0.80 \\
\hline Sustenance & $0-4$ & $1.0(1.1)$ & $\ldots$ \\
\hline Emotional transformation & $0-12$ & $5.6(3.5)$ & 0.91 \\
\hline Practice for change & $0-12$ & $3.5(2.6)$ & 0.73 \\
\hline Changes in social environment & $0-12$ & $5.9(3.7)$ & 0.78 \\
\hline
\end{tabular}

a Possible range and observed range.

Table 5 shows the results of the stepwise regression analysis to predict initiation of fruit and vegetable consumption. Behavioral confidence $(\beta=.51)$ and changes in physical environment $(\beta=.22)$ were significant predictors for the intention to initiate behavior change regarding fruit and vegetable consumption $\left(F_{2,173}=59.7 ; P<.001\right)$ with an adjusted $R^{2}$ of $40.2 \%$.

Table 6 depicts the results of the stepwise regression analysis to predict intention to sustain behavior change regarding fruit and vegetable consumption. Emotional transformation $(\beta=.18)$, practice for change $(\beta=.33)$, and changes in social environment $(\beta=.16)$ were significant predictors for the intention to sustain behavior change regarding fruit and vegetable consumption $\left(F_{3,171}=26.4 P<.001\right)$, with an adjusted $R^{2}$ of $30.4 \%$.

\section{Discussion}

The purpose of this study was to use the MTM to predict intention for behavior change regarding fruit and vegetable consumption among college students who were not eating at least 5 cups of fruits and vegetables per day.
Survey results showed that the constructs of behavioral confidence and changes in physical environment accounted for about $40 \%$ of the variance in predicting the intention to initiate behavior change regarding fruit and vegetable consumption among students. These findings are in consonance with previous studies ${ }^{15-17}$ that found that affective attitude, perceived behavioral control, and environmental factors were significant predictors of fruit and vegetable consumption. The construct of participatory dialogue was not found to be a significant predictor of intention to initiate fruit and vegetable consumption behavior change. This finding may be because the mean participatory dialogue score was 7.0 , which was moderately positive in a range of -20 to 20 , indicating that the students were already convinced that there were more advantages than disadvantages to consuming 5 cups of fruits and vegetables per day. However, there is still room to improve this construct further through MTM-based behavior-altering interventions. Future efforts to increase fruit and vegetable consumption among college students should test interventions grounded in the MTM (see Implications for Practice section). 
Table 3.

Correlations Between the Intention to Initiate Behavior Change and the Multitheory Model Initiation Constructs $(\mathbf{N}=175)$

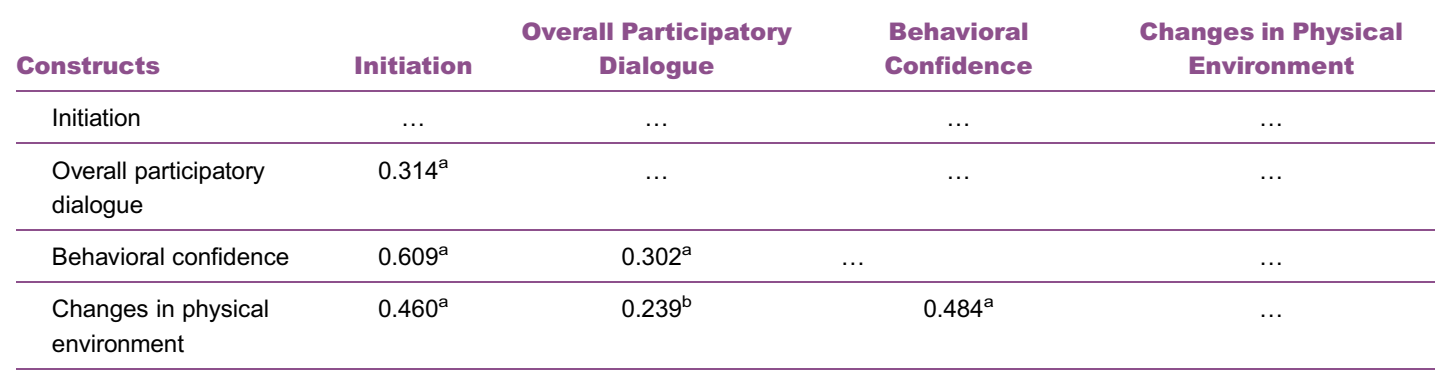

a $P<.001$

b $P=.001$.

Emotional transformation, practice for change, and changes in social environment were significant predictors for sustaining fruit and vegetable consumption, accounting for approximately $30 \%$ of the variance in intention to sustain fruit and vegetable consumption behavior. This finding provides credence to the MTM as a useful framework that can be used to develop interventions to improve fruit and vegetable consumption among college students. To our knowledge, the continuation of fruit and vegetable consumption behavior has not been studied. Acquisition or initiation of behavior change may be relatively easy, but maintaining that behavior change is challenging, particularly for behaviors that ideally entail a lifelong change. ${ }^{30}$ Future studies should reify the constructs of the sustenance model to effectively assist college students with maintaining consumption of 5 or more cups of fruits and vegetables, in accordance with USDA recommendations. ${ }^{9,10}$

The relatively low mean intention for initiation and sustenance of behavior change scores regarding fruit and vegetable consumption indicated that students were not thinking about making changes regarding their fruit and vegetable consumption. This finding shows that there is an opportunity for health education and for influencing improved dietary behavior among college students. The mean behavioral confidence score was 6.8 of a possible 20 , indicating an ardent need to build college students' confidence regarding their ability to consume 5 cups

\section{Table 4.}

Correlations Between the Intention to Sustain Behavior Change and the Multitheory Model

Sustenance Constructs $(\mathbf{N}=175)$

\begin{tabular}{|c|c|c|c|c|}
\hline Constructs & Sustenance & $\begin{array}{l}\text { Emotional } \\
\text { Transformation }\end{array}$ & $\begin{array}{l}\text { Practice for } \\
\text { Change }\end{array}$ & $\begin{array}{c}\text { Changes in Social } \\
\text { Environment }\end{array}$ \\
\hline Sustenance & $\ldots$ & $\ldots$ & $\ldots$ & $\ldots$ \\
\hline Emotional transformation & $0.460^{a}$ & $\ldots$ & $\ldots$ & $\ldots$ \\
\hline Practice for change & $0.518^{a}$ & $0.643^{a}$ & $\ldots$ & $\ldots$ \\
\hline
\end{tabular}

a $\quad P<.001$. 
Table 5.

Stepwise Regression Analysis to Predict Initiation of Fruit and Vegetable Consumption Behavior Change in College Students ${ }^{a}(\mathbf{N}=175)$

\begin{tabular}{|c|c|c|c|c|c|}
\hline Constructs & B & $\mathbf{S E}_{\mathbf{B}}$ & $\beta$ & $P$ Value & $95 \% \mathrm{CI}$ \\
\hline Behavioral confidence & 0.125 & 0.012 & 0.609 & $<.001$ & $0.101-0.150$ \\
\hline \multicolumn{6}{|l|}{ Step $2^{c}$} \\
\hline Behavioral confidence & 0.104 & 0.014 & 0.505 & $<.001$ & $0.077-0.131$ \\
\hline
\end{tabular}

a Dependent variable is initiation of fruits and vegetables consumption behavior change; Independent variables are participatory dialogue, behavioral confidence, and changes in physical environment.

b $F_{1,174}=102.7 ; P<.001 ; R^{2}=0.37 ;$ adjusted $R^{2}=0.37$.

c $F_{2,173}=59.7 ; P<.001 ; R^{2}=0.41$; adjusted $R^{2}=0.40$.

of fruits and vegetables daily by identifying sources of confidence, enhancing their enjoyment of meals rich in fruits and vegetables, overcoming financial constraints, and developing a taste for fruits and vegetables. The mean scores of constructs of the sustenance model-namely, emotional transformation, practice for change, and changes in social environment-were all on the lower end of the possible score range, highlighting the need for future interventions to build on these constructs. Survey results also showed that the mean change in social environment score was statistically significantly higher in women than men. This finding could indicate that women are more attuned to the influence of social support, and future interventions must keep this factor in mind while reifying this construct.

Table 6.

Stepwise Regression Analysis to Predict Sustenance of Fruit and Vegetable Consumption Behavior Change in College Students ${ }^{a}(\mathbf{N}=175)$

\begin{tabular}{|c|c|c|c|c|c|}
\hline Constructs & B & $\mathbf{S E}_{\mathbf{B}}$ & $\beta$ & $P$ Value & $95 \% \mathrm{CI}$ \\
\hline \multicolumn{6}{|l|}{ Step $1^{\mathrm{b}}$} \\
\hline Practice for change & 0.218 & 0.027 & 0.518 & $<.001$ & $0.164-0.272$ \\
\hline \multicolumn{6}{|l|}{ Step $2^{\mathrm{c}}$} \\
\hline Practice for change & 0.184 & 0.030 & 0.437 & $<.001$ & $0.125-0.243$ \\
\hline Changes in social environment & 0.055 & 0.021 & 0.188 & .009 & $0.014-0.095$ \\
\hline \multicolumn{6}{|l|}{ Step $3^{d}$} \\
\hline Emotional transformation & 0.056 & 0.026 & 0.183 & .030 & $0.006-0.106$ \\
\hline Practice for change & 0.139 & 0.036 & 0.331 & $<.001$ & $0.069-0.210$ \\
\hline Changes in social environment & 0.047 & 0.021 & 0.161 & .025 & $0.006-0.088$ \\
\hline
\end{tabular}

a Dependent variable is sustenance of fruits and vegetables consumption behavior change. Independent variables are practice for change, changes in social environment, and emotional transformation.

b $F_{1,173}=63.446 ; P<.001 ; R^{2}=0.268$; adjusted $R^{2}=0.264$.

c $F_{2,172}=36.375 ; P<.001 ; R^{2}=0.297$; adjusted $R^{2}=0.289$

d $F_{3,171}=26.374 ; P<.001 ; R^{2}=0.316$; adjusted $R^{2}=0.304$ 


\section{Implications for Practice}

Results of this study lend support to the operationalization of the MTM for designing and evaluating interventions for promoting fruit and vegetable consumption in college students. The first construct that is important for potential interventions to incorporate is participatory dialogue, which can be influenced by having college students participate in 2-way discussions with program facilitators that address the advantages of consuming a diet rich in fruits and vegetables. Physicians and other health care professionals can serve as effective facilitators for initiating participatory dialogue. Osteopathic physicians, especially, are in an excellent position to initiate this dialogue, as it reinforces the osteopathic tenet regarding the body's ability to self-regulate, selfheal, and maintain health. ${ }^{31}$ The body must be provided with the proper nutrition to support these processes. Building behavioral confidence can be done through educational programs that teach students positive grocery shopping habits. Taste-testing demonstrations can also be used to help students acquire taste for fruits and vegetables. The construct of changes in physical environment can be influenced by making fruits and vegetables available and convenient to obtain by offering them as options in campus dining establishments and vending machines. Furthermore, the cost of fruits and vegetables on campus would ideally be subsidized.

To build long-term changes in college students' daily consumption of fruits and vegetables, they must be taught to convert or transform their emotions toward the goal of eating an adequate number of fruits and vegetables each day. This goal may be accomplished through affective methods, such as role playing situations in which students are asked to choose between different dining or cooking options, as well as discussion with professional health educators regarding fruit and vegetable substitutions to their chosen options. The construct of practice for change can be improved by encouraging college students to monitor their behavior by keeping a log or a diary to help them identify and overcome barriers to accomplishing their goals. The construct of changes in social environment can be enhanced by integrating various forms of social support (eg, friends, family members, health care professionals) into intervention strategies. The social support can be naturally occurring or artificially created, whereby a health care professional provides support with the behavior change.

\section{Strengths and Limitations}

This study has several strengths. To our knowledge, this was the first study to use a fourth-generation approach in health behavior research, applying the MTM to examine determinants of fruit and vegetable consumption behavior change. This study uniquely focused on aspects for sustaining fruit and vegetable consumption behavior, which previous studies have not examined, to our knowledge. Also, this study demonstrated the substantial role of MTM constructs in both the intention to initiate and sustain the behavior change of consuming 5 or more cups of fruits and vegetables per day.

This study also has several limitations. The crosssectional design cannot establish a causal relationship between the independent and dependent variables because both are being measured at the same time. Also, this study relied on self-reported data, which are subject to bias. However, many of the constructs of the MTM are attitudinal and can only be measured with self-reported information. The study also used intention of behavior change both for initiation and sustenance of behavior change as proxy measures for actual behavior change. Another limitation of the study is that it did not establish test-retest of the survey. This type of reliability testing is especially important for experimental studies. Additionally, because the purpose of this study was theory testing, and internal validity was of prime concern, random sampling was not done. Therefore, the results of this study are limited by the choice of the sample, and caution must be used in generalizing the results to all college students or adults in general.

\section{Future Research}

To address some of the limitations of this study, future research should use longitudinal and experimental 
designs to establish causality between MTM constructs and fruit and vegetable consumption behavior. Additionally, researchers must aim at going beyond self-reports for constructs that can be objectively measured or observed. Although there is some empirical evidence from previous work ${ }^{32}$ with theory of reasoned action and theory of planned behavior ${ }^{33}$ that justifies the use of measuring intention for behavior change as a proxy for behavior change, actual behavior change should be measured through experimental designs. Future research should also use a random selection of participants so that generalizability can be improved.

\section{Conclusion}

Results showed that the MTM can be a useful model for implementing interventions to encourage fruit and vegetable consumption among college students. The MTM constructs of initiation-namely, participatory dialogue, behavioral confidence, and changes in physical environment - are crucial for initiating behavior change regarding fruit and vegetable consumption among college students. For sustaining such behavior, the constructs of practice for change, emotional transformation, and changes in social environment are vital.

\section{Acknowledgment}

We thank the students who participated in this study.

\section{Author Contributions}

All authors provided substantial contributions to conception and design, acquisition of data, or analysis and interpretation of data; all authors drafted the article or revised it critically for important intellectual content; all authors gave final approval of the version of the article to be published; and all authors agree to be accountable for all aspects of the work in ensuring that questions related to the accuracy or integrity of any part of the work are appropriately investigated and resolved.

\section{References}

1. Hung HC, Joshipura KJ, Hu FB, et al. Fruit and vegetable intake and risk of major chronic disease. J Natl Cancer Inst. 2004;96 (21):1577-1584. doi:10.1093/jnci/djh296

2. Yokoyama $Y$, Nishimura K, Barnard ND, et al. Vegetarian diets and blood pressure: a meta-analysis. JAMA Intern Med. 2014;174 (4):577-587. doi:10.1001/jamainternmed.2013.14547
3. Wiseman M. The second World Cancer Research Fund/American Institute for Cancer Research expert report. Food, nutrition, physical activity, and the prevention of cancer: a global perspective. Proc Nutr Soc. 2008;67(3):253-256. doi:10.1017/ S002966510800712X

4. Bazzano LA, Li TY, Joshipura KJ, Hu FB. Intake of fruit, vegetables, and fruit juices and risk of diabetes in women. Diabetes Care. 2008;31 (7):1311-1317. doi:10.2337/dc08-0080

5. Aldoori WH, Giovannucci EL, Rockett HR, Sampson L, Rimm EB, Willett WC. A prospective study of dietary fiber types and symptomatic diverticular disease in men. J Nutr. 1998;128(4):714-719. doi:10.1093/ jn/128.4.714

6. Cho E, Seddon JM, Rosner B, Willett WC, Hankinson SE. Prospective study of intake of fruits, vegetables, vitamins, and carotenoids and risk of age-related maculopathy. Arch Ophthalmol. 2008;122(6):883-892. doi:10.1001/archopht.122.6.883

7. United States Department of Agriculture. Nutrients and health benefits. Choose MyPlate website. http://www.choosemyplate.gov/ vegetables-nutrients-health. Updated January 12, 2018. Accessed June 11, 2018

8. Liu RH. Health-promoting components of fruits and vegetables in the diet. Adv Nutr. 2013;4(3):384S-392S. doi:10.3945/an.112.003517

9. United States Department of Agriculture. All about the vegetable group. Choose MyPlate website. http://www.choosemyplate.gov/ vegetables. Updated July 3, 2018. Accessed June 11, 2018.

10. United States Department of Agriculture. All about the fruit group. Choose MyPlate website. Updated January 3, 2018. Accessed June 11, 2018. http://www.choosemyplate.gov/fruit

11. Small M, Bailey-Davis L, Morgan N, Maggs $\mathrm{J}$. Changes in eating and physical activity behaviors across seven semesters of college: living on or off campus matters. Health Educ Behav. 2012;40(4):435-441. doi:10.1177/1090198112467801

12. El Ansari W, Stock C, John J, et al. Health promoting behaviors and lifestyle characteristics of students at seven universities in the UK. Cent Eur J Public Health. 2011;19(4):197-204

13. American College Health Association-National College Health Assessment II: Reference Group Undergraduates Executive Summary Fall 2016. Hanover, MD: American College Health Association; 2017.

14. Nelson MC, Story M, Larson NI, Neumark-Sztainer D, Lytle LA. Emerging adulthood and college-aged youth: an overlooked age for weight-related behavior change. Obesity. 2008;16(10):2205-2211. doi:10.1038/oby.2008.365

15. Blanchard CM, Fisher J, Sparling PB, et al. Understanding adherence to 5 servings of fruits and vegetables per day: a theory of planned behavior perspective. J Nutr Educ Behav. 2009;41(1):3-10. doi:10.1016/j.jneb.2007.12.006

16. Boucher D, Gagné C, Côté F. Determinants of the intention of post-secondary students to eat at least five servings of vegetables and fruit daily [in French]. Rev Epidemiol Sante Publique. 2012;60 (2):109-119. doi:10.1016/j.respe.2011.10.003

17. Mirabitur E, Peterson KE, Rathz C, Matlen S, Kasper N. Predictors of college-student food security and fruit and vegetable intake differ by housing type. J Am Coll Health. 2016;64(7):555-564. doi:10.1080/ 07448481.2016 .1192543

18. Adams TB, Colner W. The association of multiple risk factors with fruit and vegetable intake among a nationwide sample of college students. 
J Am Coll Health. 2008;56(4):455-461. doi:10.3200/ JACH.56.44.455-464

19. Kelly NR, Mazzeo SE, Bean MK. Systematic review of dietary interventions with college students: directions for future research and practice. J Nutr Educ Behav. 2013;45(4):304-313. doi:10.1016/j. jneb.2012.10.012

20. Deliens T, Van Crombruggen R, Verbruggen S, De Bourdeaudhuij I, Deforche B, Clarys P. Dietary interventions among university students: a systematic review. Appetite. 2016;105:14-26. doi:10.1016/j. appet.2016.05.003

21. Sharma M. Multi-theory model (MTM) for health behavior change. Webmed Central Behaviour. 2015;6(9):WMC004982.

22. Sharma M, Romas JA. Theoretical Foundations of Health Education and Health Promotion. Sudbury, MA: Jones \& Bartlett Learning; 2017.

23. Knowlden AP, Sharma M, Nahar VK. Using multitheory model of health behavior change to predict adequate sleep behavior. Fam Community Health. 2017;40(1):56-61. doi:10.1097/ $\mathrm{FCH} .0000000000000124$

24. Nahar VK, Sharma M, Catalano HP, Ickes MJ, Johnson P, Ford MA. Testing multi-theory model (MTM) in predicting initiation and sustenance of physical activity behavior among college students. Health Promot Perspect. 2016;6(2):58-65. doi:10.15171/ hpp.2016.11

25. Sharma M, Catalano HP, Nahar VK, Lingam V, Johnson P, Ford MA Using multi-theory model to predict initiation and sustenance of small portion size consumption among college students. Health Promot Perspect. 2016;6(3):137-144. doi:10.15171/hpp.2016.22

26. Sharma M, Catalano HP, Nahar VK, Lingam V, Johnson P, Ford MA Applying multi-theory model (MTM) of health behavior change to predict water consumption instead of sugar sweetened beverages. J Res Health Sci. 2017;17(1):e00370.

27. DeVilles RF. Scale Development: Theory and Applications. 4th ed Newbury Park, CA: Sage Publications; 2017:39-82.

28. Tabachnick BG, Fidell LS. Using Multivariate Statistics. 5th ed. Boston MA: Pearson; 2007:607-675

29. Sharma M, Petosa RL. Measurement and Evaluation for Health Educators. Burlington, MA: Jones \& Bartlett Learning; 2014:126-139.

30. Sharma M, Branscum P, Atri A. Introduction to Community and Public Health. San Francisco, CA: Jossey-Bass; 2014.

31. Tenets of osteopathic medicine. American Osteopathic Association website. http://www.osteopathic.org/inside-aoa/about/leadership/ Pages/tenets-of-osteopathic-medicine.aspx. Accessed June 20, 2018.

32. Fishbein M. A theory of reasoned action: some applications and implications. Nebr Symp Motiv. 1980;27:65-116.

33. Ajzen I, Driver BL. Prediction of leisure participation from behavioural, normative, and control beliefs: an application of the theory of planned behavior. Leisure Sci. 1991;13(3):185-204. doi:10.1080/ 01490409109513137

() 2018 American Osteopathic Association

\section{Rapid Review}

The Journal of the American Osteopathic Association considers manuscripts for rapid review when appropriate. Authors must justify their rapid review requests in their cover letters. Rapid review is reserved primarily for original contributions and reviews of high importance to the osteopathic medical profession. However, the editor in chief will assess each rapid review request on a case-by-case basis. For more information on submitting manuscripts to the JAOA, visit http://jaoa.org/ss/mssubmission.aspx. 